\section{Absorption and Excretion}

To obtain some idea of the absorption and excretion of the drugs in man the blood concentrations were estimated at the end of the course of drug administration. For the purpose of comparison similar investigations were carried out in five patients who received similar dosages of sulphanilylguanidine (S.A.G.). The results are shown in Table III, from which it will be seen that the concentration of S.A.B. is roughly four times that of S.A.G. and that $20 \%$ of this is acetylated, as compared with $34 \%$ of S.A.G. With full dosage of S.A.A.B. the concentration is about $30 \%$ more than that of S.A.G., and $24 \%$ is acetylated. Blood concentration with the half dose is almost as high as with the full. S.S. in full doses gave only one-half the concentration of S.A.G., and of this $29.3 \%$ was acetylated.

In addition to the blood estimations a differential white cell count was carried out before, during, and after treatment in the earlier part of each series; but as no significant changes were observed this practice was later abandoned.

The drugs are rapidly excreted in the urine, specimens of which were examined for free and acetylated drug at the same times as the blood estimations. These figures are given in Table III, together with comparative values for S.A.G. In a few cases urine was again tested for presence of S.A.B. and S.A.A.B. 24 hours after cessation of treatment, and was found to contain none with the former and only about $25 \mathrm{mg}$. (total) per $100 \mathrm{c} . \mathrm{cm}$. with the latter drug. This had disappeared after a further 24 hours.

Toxic Symptoms.-Apart from slight anorexia in adults, especially at the beginning of treatment, possibly due to the large initial dose, none were observed.

\section{Discussion}

Although the rapid arrest of the diarrhoea and clearance of Bact. sonnel from the stools and rectal swabs of this series of cases, some of which had been persistently positive for a month or more, are striking, the occurrence of 24 cases in which there was bacteriological relapse is disappointing. Intermittency of excretion is obviously a troublesome problem for the hospital administrator who has to decide how many successive negative cultures are necessary before the patient can be considered free of infection.

Working with sulphapyridine in smaller doses than those employed in this series, one of us (Swyer, 1943) found that in a series of 57 cases no bacteriological relapses occurred after 3 days of the negative state, but among 35 controls 6 such relapses developed at periods ranging from 7 to 36 days after apparent clearance. Yannet and his colleagues (1942), on the other hand, reported that in an outbreak of 44 cases of Sonne dysentery in an institution, of which 27 were treated with sulphathiazole, the time needed to obtain bacteriological clearance was actually longer in the drug-treated cases than in controls. Although in the chemotherapy of intestinal infections in which the infecting organism is not found in the blood stream preference is given to drugs of a low degree of absorption, it is worthy of note that in the three series recorded here and the sulphapyridine series quoted above, the efficacy of- the drug, particularly in clearing up carriers, was in direct proportion to the degree of absorption of drug from the intestine.

\section{Summary}

In the above series 179 patients suffering from bacteriologically proved Sonne dysentery have been treated with sulphanilylbenzamide, sulphanilylamidobenzamide, or succinyl sulphathiazole in doses governed by the patients' weight. The stools became formed, normal in colour, and free from blood or mucus in 24 to 48 hours in the S.A.B. series, and in 38 of these cases bacteriological clearance was obtained in an average of 1.8 days. Improvement in characteristics of stools was marked with S.A.A.B., but rather less so than with S.A.B. The average time for clearance was 3.6 and 2.5 days with full- and half-dosage respectively. With S.S. there was not a great improvement in stools, but clearance time was 2.4 days. Bacteriological relapse rates were: with S.A.B., $7.3 \%$; S.A.A.B., full dose $15 \%$, and half dose $3.3 \%$; S.S., $34.6 \%$.

We have to thank Messrs. Burroughs Wellcome for supplies of S.A.B. and S.A.A.B., and Dr. Prescott and his colleagues of the Wellcome Research Institution for information regarding the chemistry of and animal experiments with the drugs; Dr. R. Cruickshank and staff in the North-Western Group Laboratory, L.C.C.; and Mr. L. G. C. Maslen of the North-Eastern Hospital Laboratory for carrying out the large number of bacteriological, haematological, and biochemical investigations involved in this work. We are also grateful to members of the nursing staff for willing co-operation and help.

REFERENCES

Brownlee, G., and Tonkin, M. (1941). Nature, 148, 167.
Cruickshank, R., and Swyer, R. (1940). Lancet, 2, 803.

Cruickshank, R., and Swyer, R. (1940). Lanc

Swyer, R. (1943). Lancet, 2, 71.

Yannet, H., Leibovitz, A., and Deutsch, J. V. (1942). J. Amer. med. Ass., 120, 184.

\section{HAEMOLYTIC DISEASE OF THE NEWBORN IN. ONE OF DIZYGOTIC TWINS}

BY

F. STRATTON, M.D., D.P.H.

Regional Transfusion Service, Manchester

F. A. LANGLEY, M.Sc., M.B.

Department of Pathology, University of Manchester

AND

\section{U. LISTER, M.B.}

Crumpsall Hospital, Manchester

The occurrence of haemolytic disease in both children of twins is well known (Snyder and Ford, 1941; Buhler, Seely, and McCormick, 1942), but the occurrence of the disease in one of the twins, the other being normal, is less well known. Macklin (1939) collected six such cases from the literature, but in three instances it seemed likely that both children were affected.

The aetiological connexion between the $\mathrm{Rh}$ factor and haemolytic disease, and the iso-immunization theory developed by Levine, Burnham, Katzin, and Vogel (1941) to explain this association, supersede the earlier theories of Macklin (1939) and Darrow (1938). Since this theory was formulated, twins affected with haemolytic disease have been described by Buhler, Seely, and McCormick (1942); the children were Rh-positive, as was the father, the mother was Rh-negative, and her serum contained $\mathrm{Rh}$ antibodies. Langley and Stratton (1944) reported a case in which an Rh-negative mother gave birth to twins, both affected and both $\mathrm{Rh}$-positive. The maternal serum contained strong $\mathrm{Rh}$ agglutinins. Since then those authors have studied two further cases of twin pregnancy in which both children were affected. In each instance the maternal blood was $\mathrm{Rh}$ negative and contained $\mathrm{Rh}$ iso-agglutinins, while all the children were of genotype $\mathrm{Rh}_{1} \mathrm{rh}$.

Kariher (1943) reported a case of binovular twins whose mother was $\mathrm{Rh}$-negative, her serum containing $\mathrm{Rh}$ antibodies; and while the unaffected child was Rh-negative, the affected child was Rh-positive, the diagnosis being made clinically and confirmed at necropsy. Potter (1944) has reported a doubleovum pregnancy in which one infant was normal but the other died of erythroblastosis on the second day of life. The maternal blood contained no anti-Rh agglutinins, but was $\mathrm{Rh}$-negative; the living child was $\mathrm{Rh}$-negative and the dead one Rh-positive.

The following case is described because it was studied clinically, pathologically, and serologically; morecver, it is of interest, as although only one child was affected both were Rh-positive.

\section{Case Report}

Mrs. X., aged 28, was delivered five years ago of an infant which has been completely normal; there was no history of abortions. When first seen in June, 1944, she was found to have a twin pregnancy, the estimated date of delivery being Aug. 20. Her general condition was satisfactory. Four weeks before the expected date she was delivered in hospital, after a normal labour, of a female child weighing $3 \mathrm{lb} .10 \mathrm{oz}$. and a male child weighing $4 \mathrm{lb}$.

Both children cried immediately and were vigorous. There were two placentae with separate amniotic sacs. Within six hours of birth the male child showed jaundice of a canary-yellow colour; 12 hours later this had increased in intensity. Twenty-eight hours after delivery the haemoglobin was $70 \%$ and the red cells $3,120,000$ per c.mm. Vitamin $K(5 \mathrm{mg}$.) was given intramuscularly. An attempt to give a blood transfusion was a failure. On the third day his haemoglobin was $42 \%$ and the red cells $1,850,000$ per c.mm. 
A further attempt at blood transfusion into the tibial bone marrow was unsuccessful, and the child died on the fourth day.

The female twin gained weight steadily, never showed any jaundice, pallor, or other abnormality, and on the fifth day haematological examination showed: haemoglobin $100 \%$, red cells $5,000,000$ per c.mm. When 6 weeks old she weighed $5 \mathrm{lb} .8 \mathrm{oz}$. A blood count showed haemoglobin $70 \%$ and red cells $4,000,000$ per c.mm.

Pathology.-The relevant post-mortem findings were as follows: Naked-eye:-The skin and mucous membranes were deeply jaundiced (bright yellow). Blotchy haemorrhages were present in the lung, and there were a few small haemorrhages on the peritoneal surface of the gut. Bile was present in the intestine. The liver was enlarged and deeply jaundiced; the bile ducts were normal. The spleen was enlarged and firm. The brain was pale. The other organs showed no abnormality, except bile-staining.

Microscopic:-Many of the liver cells were vacuolated as by fat, and about half the remainder showed the clear watery. appearance of glycogen infiltration. The reticulum framework was normal. There was widespread haemosiderosis. Bile thrombi were present in the intercellular canaliculi. Fairly numerous foci of haemopoiesis were found outside the sinusoids. These were mostly erythropoietic, though there were a few myelocytes. Primitive blood cells were also present in the sinusoids. There was marked leucopoiesis in the portal tracts, but there were also some erythropoietic foci. The general architecture of the spleen was normal. There was a fairly intense leucopoiesis, but only scanty erythropoiesis. The kidney showed subcapsular glomeruli incompletely developed; no haemopoiesis. The blood in the vessels of the liver and kidney contained many nucleated red cells.

Serology.-The Wassermann reaction in the mother was negative. The results of examination of the erythrocytes of children and mother were as follows:

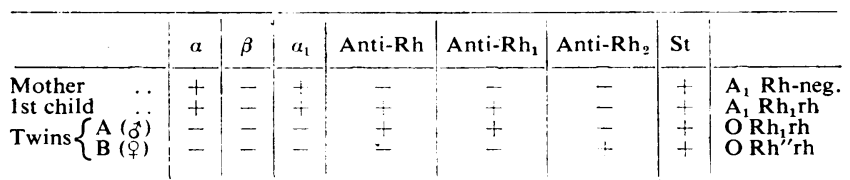

The maternal serum contained a weakly active $\mathrm{Rh}$ antibody when first tested on the second day after delivery. When retested a month after delivery the $\mathrm{Rh}$ agglutinins were much stronger, and titration at $37^{\circ} \mathrm{C}$. gave the following results:

\begin{tabular}{c|c|c|c|c|c|c|c}
\hline Cells & $\mathrm{Rh}_{1} \mathrm{Rh}_{2}$ & $\mathrm{Rh}_{1} \mathrm{rh}$ & $\mathrm{Rh}_{2} \mathrm{rh}$ & $\mathrm{Rh}_{1} \mathrm{Rh}_{1}$ & $\mathrm{Rh}^{\prime} \mathrm{rh}$ & $\mathrm{Rh}^{\prime \prime} \mathrm{rh}$ & $\mathrm{Rh}$-neg. \\
\hline Titre & 64 & 32 & 16 & 64 & 4 & 0 & 0 \\
\hline
\end{tabular}

\section{Comment}

The male twin was considered to be affected with haemolytic disease, the diagnosis being based on the clinical, haematological, and pathological data. The picture was that of a jaundiced newborn second child with a progressively severe anaemia in the absence of syphilis, sepsis, or haemorrhage, resulting in the death of the child. In the haematological data the normoblast count was unfortunately not recorded, but at necropsy the liver and kidney blood vessels contained many nucleated red cells. Prematurity, confirmed by the incomplete glomerular development and hepatic glycogen infiltration, rendered the interpretation of the histological appearances difficult. Haemopoiesis was, however, rather more intense than is usual with this degree of prematurity, and there were marked splenic leucopoiesis and excessive portal erythropoiesis. All the above findings are consonant with a diagnosis of haemolytic disease of the newborn.

The female child is considered to be healthy and unaffected by the haemolytic disease. Any suggestion that the above might be a mild case is negatived by the clinical and haematological findings.

The blood group $\mathrm{Rh}$ has been shown (Wiener, Sonn, and Belkin, 1944 ; Race, Taylor, Boorman, and Dodd, 1943 ; Race, Taylor, Cappell, and McFarlane, 1944) to consist of many subtypes, or, more correctly, the $\mathrm{Rh}$ gene is an example of multiple allelomorphism. In differentiating the types of $R h$ certain human sera are used. In this family the mother is Rh-negative (rhrh), while the affected child was of genotype $\mathrm{Rh}_{1} \mathrm{rh}$; the unaffected one is $\mathrm{Rh}^{\prime \prime} \mathrm{rh}$. It seems that the father is therefore $R h_{1} R h^{\prime \prime}$.

The maternal $R h$ antibodies are of the type anti- $\mathrm{Rh}^{\prime}$, and showed a considerable rise in titre during the first few weeks after birth of the child. It will be seen that while they react strongly with cells of a genotype similar to that of the affected child, they completely failed to react with erythrocytes of a genotype like those of the unaffected infant.

In previous cases described (Potter, 1944 ; Kariher, 1943) the unaffected child has been of the same group as the motherthat is, Rh-negative - and therefore quite incapable of reacting with $\mathrm{Rh}$ antibodies in the maternal serum. In this case, however, the child is Rh-positive, and it seems that the mother has failed to respond adequately to this stimulus-hence a normal child.

These observations afford substantial confirmation of the theory of Levine et al. (1941) that iso-immunization of the mother by "dominant hereditary blood factors" seems necessary for the child to be affected.

\section{Summary}

A case of haemolytic disease of the newborn is described in one of dizygotic twins, both being Rh-positive but of different genotypes.

The affected child became jaundiced within six hours of birth and died four days later, post-mortem findings confirming the diagnosis.

The $\mathrm{Rh}$ agglutinins detected in the maternal blood correspond to sensitization by the affected child, thus confirming the iso-immunization theory.

Our thanks are due to Prof. S. L. Baker, Dr. Ramsey, and Dr. J. F. Wilkinson for permission to publish this case. We are indebted to Dr. G. L. Taylor for a supply of St serum.

\section{REFERENCES}

Buhler, V. B., Seely, C. W., and McCormick, C. (1942). J. Missouri med. Ass., 39, 106.

Darrow, R. R. (1938). Arch. Path., 25, 378.

Kariher, D. H. (1943). J. Amer. med. Ass., 122, 943.

Langley, F. A and Stratton, F. (1944). Lancet, 1, 145.

Levine, P., Burnham, L., Katzin, E. M., and Vogel, P. (1941). Amer. J. Obstet. Gynec., 42, 925.

Macklin, M. T. (1939). Ibid.. 38, 14

Potter, E. L. (1944), J. Pediat., 24, 449.

Race, R. R., Taylor, G. L., Boorman, K. E., and Dodd, B. E. (1943). Nature, 152, 563.

Snyder, D. Cappell, D. F., and McFarlane, M. N. (1944). Ibid., 153, 52.

Wiener, A. S., Sonn, E. B., and Belkin, R. B. (1944). J. exp. Med., 79, 235.

\section{Medical Memoranda}

\section{Impetigo treated with Sodium Penicillin Gream}

In view of the present overcrowding in Service conditions the following case record may be of some interest.

On July 12, 1944, a rating complained of a rash on his face which was irritable, wet, and spreading. This on examination showed typical raised yellow crusts and was diagnosed as impetigo. Treatment was started by de-scabbing with warm eusol, thoroughly drying, and applying twice daily a paint consisting of acriflavine $1 / 2 \mathrm{gr}$., tannic acid $20 \mathrm{~g}$., and water to $1 \mathrm{oz}$.

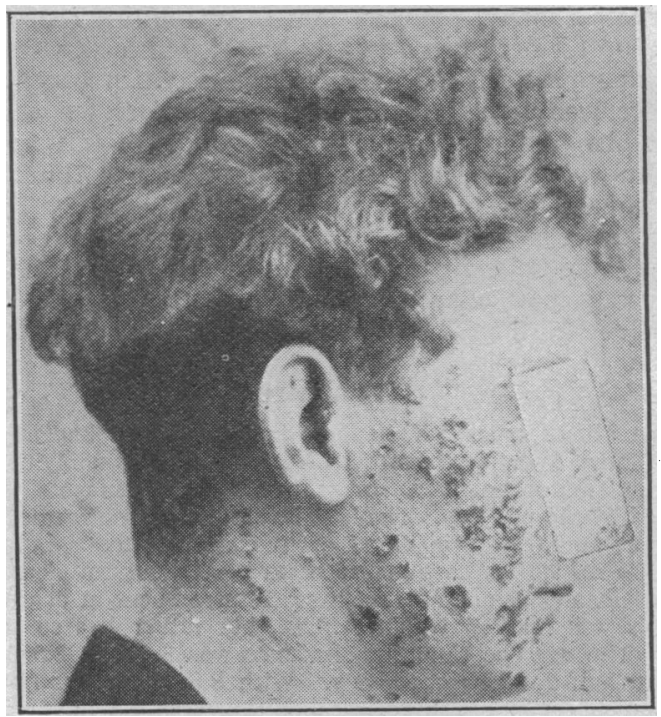

Fig. 1

In spite of treatment the condition continued to spread, and ung. hydrarg. ammon. dil. was tried without effect. On July 21 the patient was admitted to sick quarters, when Fig. 1 was taken. 